\title{
RACIONALIDADE E VULNERABILIDADE. ELEMENTOS PARA A REDEFINIÇÃO DA SUJEIÇÃO MORAL
}

\author{
Sônia T. Felipe*
}

RESUMO - A filosofia moral tradicional estabelece o critério da posse da razão como exigência para a definição da pertinência ou não de um sujeito à comunidade moral humana, e, pois, a ser considerado digno de respeito ético e justiça. Contrariando a tradição moral, Kenneth E. Goodpaster, Tom Regan e Paul W. Taylor redefinem a constituição da comunidade moral e o alcance da justiça, estabelecendo a perspectiva dos que são afetados pelas ações morais, não a dos sujeitos morais agentes, como a referência para se tomar decisões éticas relativas à justiça. Enquanto a filosofia moral tradicional considera apenas a categoria dos sujeitos morais agentes, estes autores desdobram a sujeição moral em duas possibilidades: a da agência e a da paciência moral. Com este desdobramento, mantêm-se a estatura dos agentes racionais como responsáveis pela moralidade, enquanto a vulnerabilidade às ações e decisões dos sujeitos morais agentes é levada em conta, permitindo a inclusão na comunidade moral e da justiça de interesses nãoracionais, de animais e ecossistemas nãoanimados, por exemplo.

PALAVRAS-CHAVE - Agentes morais. Pacientes morais. Agência moral. Paciência moral. Responsabilidade. Vulnerabilidade. Kenneth E. Goodpaster. Tom Regan. Paul W. Taylor
ABSTRACT - Traditional moral philosophy establishes reason as the only criterion for someone being morally considerable or recognized as member of the moral community. In contrast, Kenneth E. Goodpaster, Tom Regan and Paul W. Taylor do not agree with the moral tradition. On their perspective, the standpoint not of the agent but of the "patient" should be the central question of ethics in defining to whom principles of morality apply. While traditional philosophy operates only with the category of moral agents, these authors operates with both categories, moral agent and moral patient. They maintain that responsibility is the most significant question in defining the framework of human morality, a necessary condition to someone being considered a moral agent, possible only for rational beings, while vulnerability is the condition of being subjected to moral decisions and actions, independently of being rational or non rational. Being subjected to human morality is not a prerogative of rational beings. There are non rational interests common to humans, animals and plants, the inherent worth of life, for example, that are continuously subjected to human decisions. So, those have to be considered by ethics and justice. In order to be morally considerable it is not necessary to be rational, it is sufficient to be vulnerable to moral agency.

KEY WORDS - Moral agent. Moral patient. Moral agency. Moral patience. Responsibility. Vulnerability. Kenneth E. Goodpaster. Tom Regan. Paul W. Taylor.

Trabalho apresentado na XII Reunião da ANPOF, em Salvador, em 25 de outubro de 2006, no GT de Ética e Filosofia política.

Professora e pesquisadora de Ética e Teorias da Justiça, no Departamento de Filosofia da UFSC Orienta dissertações de Mestrado e teses de doutorado em Filosofia e no Programa de Doutorado Interdisciplinar em Ciências Humanas, da UFSC. Autora de Por uma questão de princípios: alcance e limites da ética de Peter Singer em defesa dos animais. Florianópolis: Boiteux, 2003; e de Ética e experimentação animal: argumentos abolicionistas. Florianópolis: Edufsc, 2006.

\begin{tabular}{|l|l|l|l|l|l|}
\hline VERITAS & Porto Alegre & v. 52 & n. 1 & Março 2007 & p. 184-195 \\
\hline
\end{tabular}




\section{A configuração tradicional da comunidade de sujeitos morais}

Na Ética a Nicômaco, Aristóteles estabelece os limites da comunidade à qual suas lições se destinam: a dos homens, o equivalente a sujeitos racionais do sexo masculino, nascidos em Atenas, proprietários e livres. Sem o dote de uma vontade livre, uma vontade que pode fazer o que a razão determina sem necessidade do mando alheio, não há sujeito moral. Por destinar-se a formar um segundo caráter nos sujeitos que têm aquelas outras qualidades, a ética aristotélica visa apenas os sujeitos dotados de vontade livre, os únicos para os quais o agir representa a expressão da racionalidade levada ao mais alto grau de excelência. A ética da excelência não pára de influenciar o pensamento ao longo dos séculos que separam o texto de Aristóteles e o texto de Kant, escrito no final do século XVIII. Analogamente ao feito por Aristóteles, também Kant reconhece a liberdade da vontade de seres racionais como a capacidade que define o caráter de quem se constitui como sujeito e, pois, membro da comunidade moral. ${ }^{1}$ Resumindo: em Aristóteles e em Kant, a comunidade moral é constituída apenas por sujeitos dotados de razão, compreendendo-se, nesse conceito, a capacidade de pensamento, consciência e linguagem.

\section{Os limites da configuração tradicional}

Seguindo-se a tradição filosófica, apenas seres racionais fazem parte da comunidade moral. Isso significa: apenas seres racionais têm direitos morais, o que significa, apenas sujeitos racionais constituem a comunidade para a qual a justiça na distribuição de bens é pensada. A prerrogativa de ser sujeito de direitos se configura através da capacidade de reconhecer e assumir deveres. Quem não pode entender nem aceitar o que seja praticar uma ação por dever, ainda que o faça somente conformemente ao dever (por obrigação) não pode ser considerado membro da comunidade moral, pelo menos não pela via do argumento dos deveres morais diretos de consideração. A comunidade moral, conforme vista na tradição filosófica, constitui-se exclusivamente de sujeitos morais. Direitos e deveres são duas faces da mesma liberdade num sujeito moral. ${ }^{2}$ Rousseau as expõe claramen-

“[...] pois o que constitui o valor particular de uma vontade absolutamente boa, valor superior a todo o preço, é que o princípio da ação seja livre de todas as influências de motivos contingentes que só a experiência pode fornecer. [...] A vontade é concebida como a faculdade de se determinar a si mesmo a agir em conformidade com a representação de certas leis. E tal faculdade só se pode encontrar em seres racionais." KANT, Fundamentação da metafísica dos costumes. São Paulo: Abril Cultural, 1980, p. 133-134.

A concepção kantiana pode ser vista nesta formulação: "Seres racionais estão, pois, todos submetidos a esta lei que manda que cada um deles jamais se trate a si mesmo ou aos outros simplesmente como meios, mas sempre simultaneamente como fins em si. [...] Mas um ser racional pertence ao reino dos fins como seu membro quando é nele em verdade legislador universal, estando porém também submetido a estas leis. Pertence-lhe como chefe quando, como legislador, não está submetido à vontade de outro." KANT, FMC, p. 139. 
te, ao configurar o cidadão ${ }^{3}$ em suas duas grandes manifestações morais: ser capaz de fazer a lei, e ser capaz de obedecê-la. Direitos e deveres requerem tais habilidades, por isso, só os têm, quem as tem. Esta é a tese moral tradicional.

Se consideramos que apenas sujeitos dotados de racionalidade (Rawls a concebe como personalidade moral) têm direitos morais e sua contrapartida, deveres morais, devemos levar em conta que muitos humanos (denominados, respectivamente, por Jan Narveson e Tom Regan, humanos marginais e humanos nãoparadigmáticos) ficam destituídos do estatuto de sujeitos morais por sua visível incapacidade tanto para assumir deveres quanto para reconhecer os próprios direitos. ${ }^{4}$ Tiramos do âmbito da moralidade, então, os recém-nascidos, as crianças muito pequenas, os adultos seqüelados por lesões neurológicas degenerativas da consciência de si, os senis e os que nascem com limitações mentais abrangentes. A filosofia moral tradicional exclui todos os seres humanos em condições racionais debilitadas do âmbito de quaisquer contratos. Incapacitados em sua personalidade moral, ${ }^{5}$ esses indivíduos não se constituem como sujeitos de direitos morais, não têm deveres morais, não assumem a responsabilidade moral, política e jurídica por suas próprias ações ou pelos desdobramentos delas. Enfim, são seres humanos

3 Em Rousseau pode-se ler a seguinte passagem: "Enfim, cada um dando-se a todos não se dá a ninguém e, não existindo um associado sobre o qual não se adquira o mesmo direito que se lhe cede sobre si mesmo, ganha-se o equivalente de tudo que se perde, e maior força para conservar o que se tem. [...] Essa pessoa pública, que se forma, desse modo, pela união de todas as outras, tomava antigamente o nome de cidade e, hoje, o de república ou de corpo político, o qual é chamado por seus membros de Estado quando passivo, soberano quando ativo, e potência quando comparado a seus semelhantes. Quanto aos associados, recebem eles, coletivamente, o nome de povo e se chamam, em particular, cidadãos, enquanto partícipes da autoridade soberana, e súditos enquanto submetidos às leis do Estado." ROUSSEAU, Do contrato social. 2 ed. São Paulo: Abril Cultural, 1978; p. 33-34.

4 Alan White compreende o risco moral de tal limitação. Por isso, mesmo estabelecendo critérios bastante fortes para indicar o uso devido da categoria direitos, não exclui bebês humanos ou outros incapazes de assumir o dever que o direito impõe. "De um direito, diz-se que é algo para ser exercido, recebido, gozado ou dado, que pode ser declarado, exigido, atribuído, reivindicado, assegurado, renunciado, abdicado; pode haver um direito de fazer isso e aquilo, ou de ter isso ou aquilo feito em favor de alguém, estar em um certo estado, ter uma certa emoção, ou adotar uma certa atitude. Um direito é relativo, e contrapõe-se a um dever, a uma obrigação, a um privilégio, a um poder, a uma responsabilidade. Um sujeito possível de direito é então, o que propriamente pode ser expresso nessa linguagem; isto é, aquele do qual se pode inteligivelmente dizer, seja verdadeira ou falsamente, que é capaz de exercer, usufruir, etc. um direito, ter um direito a tais coisas diversas, ter deveres, privilégios, etc. Além disso, [...] uma condição necessária para que um ser qualquer seja capaz de ter um direito a V, é que seja capaz de V." WHITE, Alan. Why animals cannot have rights. In: REGAN, Tom; SINGER, Peter. Animal rights human obligation. $2^{\text {nd }}$. New Jersey: Prentice Hall, 1989, p. 120.

5 Para conceber a justiça, Rawls presume que a posição que a concebe seja tomada por sujeitos capazes de "fazer propostas, apresentar razões par a sua aceitação e assim por diante. Naturalmente a finalidade dessas condições é representar a igualdade entre os seres humanos como pessoas éticas, como criaturas que têm uma concepção do seu próprio bem e que são capazes de ter um senso de justiça. Toma-se como base da igualdade a similaridade nesses dois pontos. [...] supõe-se que cada homem tenha a capacidade necessária para entender quaisquer princípios que sejam adotados e agir de acordo com eles." RAWLS, John. Uma teoria da justiça. São Paulo: Martins Fontes, 1997, p. 21. 
destituídos da estatura moral necessária para compor a comunidade moral. Esta é a tese tradicional contratualista.

Para enfrentar o mal que tal exclusão representa àqueles sujeitos destituídos de personalidade moral, a filosofia moral tradicional inventa uma segunda teoria, em reparo aos buracos deixados pela teoria da posse da personalidade moral plena como condição necessária e suficiente de ingresso no âmbito dos benefícios da justiça. Essa segunda teoria, necessária a todas as éticas de matriz perfeccionista ou contratualista, é a da potencialidade. Indivíduos destituídos da potência racional não são excluídos automaticamente da comunidade moral humana, porque se reconhece sua potencialidade para a posse da razão, embora seja evidente sua incapacidade prática para operar com as habilidades que caracterizam a racionalidade: pensamento formal, linguagem articulada por uma gramática, consciência de si, interação e criação propiciadoras do provimento físico e mental característicos do padrão paradigmático da espécie humana.

A tese da potencialidade racional como requisito suficiente para que se possa incorporar um sujeito à comunidade de sujeitos racionais, que constitui o âmbito da moralidade ao qual se dedica a tarefa do filosofar, remenda o tecido roto da filosofia moral tradicional racionalista, mas não dá conta de fundar uma ética genuína, nem humanista, nem animalista, nem ambientalista. Ao exigir a posse plena da razão como condição necessária e suficiente para que um sujeito possa ser considerado digno de consideração moral, abandonando essa exigência, assim que se apresenta o caso de um humano, que não a pode cumprir, mas, permitindo, por outro lado, que esse sujeito incapaz permaneça no âmbito antes afirmado como exclusivo de quem possui a plena posse da razão, a teoria ética entra em contradição, ferindo as exigências de universalidade, generalidade e imparcialidade, que configuram um princípio como válido racionalmente. Segue-se ou suspende-se de forma tendenciosa a exigência, quando ela reforça ou ameaça desvelar o viés racionalista antropocêntrico-hierárquico que sempre cultivou ao construir a teoria da moralidade humana.

Por outro lado, ao suspender a exigência, quando se trata de considerar os interesses de humanos incapazes de se articularem racionalmente, mas deixando de considerar que esses interesses são comuns a humanos e a não-humanos, a filosofia moral tradicional revela sua autêntica natureza: é uma proposta de configuração de um segundo caráter na natureza humana, tendo como pressuposto que o que é humano centra-se na habilidade da razão, seja factual, seja potencial. Destituídos dessa habilidade, não fazem parte do grupo de seres em relação aos quais os sujeitos morais têm deveres diretos de consideração moral.

Para evitar o estímulo à violência e crueldade que sua matriz racional pode causar naqueles que, por serem dotados de razão, se sentem no direito de fazer o que bem entendem com os destituídos de razão, a filosofia moral tradicional recorre a dois conceitos de deveres morais: diretos e indiretos. Sujeitos morais têm deveres diretos em relação a outros sujeitos morais, mas, em relação a outros 
sujeitos destituídos de racionalidade; se houver algum dever de respeito, este será por uma razão indireta, conforme o diz Kant, por razão à humanidade que os sujeitos morais agentes querem preservar em si mesmos e nos demais que lhes são iguais. Os seres destituídos de razão não são preservados em sua integridade física ou psíquica em nome do valor ou do bem que a vida tem para si, mas por haver um sujeito moral agente cujo apreço pela própria natureza racional não admite agir de forma incoerente.

Animais e ecossistemas vegetais, dado que não têm, nem de fato nem potencialmente atividade racional, não foram incluídos pelos filósofos morais tradicionais no âmbito da comunidade moral humana pela via dos deveres diretos. O dever de respeito à sua natureza específica deve-se ao fato de que sujeitos morais, dotados da plena posse da razão, têm algum interesse em preservá-los, portanto, pela via dos deveres indiretos de respeito.

Enquanto mantivermos esse modelo que funda na posse da razão a condição para que um indivíduo possa ser incluído no âmbito da comunidade moral, enquanto esta for constituída apenas por sujeitos morais agentes, estaremos fazendo ética para contemplar apenas os interesses de sujeitos racionais. Humanos impedidos de racionalidade, animais não-humanos e ecossistemas vegetais continuam desprotegidos moralmente frente ao domínio antropocêntrico, hierárquico e tirânico do sujeito racional. Para este sujeito tirânico, iguais são apenas os que refletem as mesmas habilidades que julga definirem sua condição privilegiada frente às condições não-lingüísticas nas quais as demais espécies vivas se configuram, com seus respectivos padrões de bem-estar e plenitude específicas.

O limite da filosofia moral tradicional pode ser apontado no conceito mesmo de sujeito. Para ela, sujeito da justiça é sujeito moral, e este é sujeito racional. O filósofo moral tradicional esquece que o conceito de sujeito moral evoca o de sujeição moral. Por um lado, ela é sujeição de alguém à própria vontade que quer a ação, e, por outro, a sujeição à qual outros estão submetidos à vontade deste alguém. Sujeito pode ser, portanto, quem age motivado pelo próprio querer orientado pela razão, conforme o entende Kant; mas, também está sujeito à moral aquele que sofre os desdobramentos de uma ação sem que a tenha querido, sem que a tenha planejado, sem que a tenha podido impedir.

Ao usar os termos agente e paciente moral, ou, conforme o faz a linguagem comum, agente e vítima, indicam-se duas formas de expressão da vontade numa determinada ação. A ação pode ter origem em um dos sujeitos, o agente; mas, para ser uma ação, ela atinge um outro na condição de paciente. ${ }^{6}$ Se compreen-

Tom REGAN assim o define: "Moral agents are individuals who have a variety of sophisticated abilities, including in particular the ability to bring impartial moral principles to bear on the determination of what, all considered, morally ought to be done and, having made this determination, to freely choose or fail to choose to act as morality, as they conceive is, requires. Because moral agents have these abilities, it is fair to hold them morally accountable for what they do, assuming that the circumstances of their acting as they do in a particular case do not dictate otherwise. [...] 
demos o conceito de interação como indicando três formas de ação que afetam outros, a praticada com outros, a praticada contra outros, ou a praticada em favor de outros, ${ }^{7}$ podemos entender que um sujeito moral é o sujeito que age, ou a favor de outro, ou contrario o interesse de outro, ou junto com outro, havendo, pois, sujeitos morais agentes e pacientes morais (agentes e pacientes morais), em toda e qualquer interação humana. Seguindo-se esse raciocínio, não há como pensar a justiça, a não ser considerando que os afetados pelos desdobramentos das ações justas ou injustas devem ser levados em conta no estabelecimento dos princípios da justiça na posição original. ${ }^{8}$

Para fazer parte da comunidade moral, na perspectiva conseqüencialista nãotípica do contratualismo rawlsiano, basta estar sujeito aos desdobramentos das ações dos sujeitos morais. Basta estar sujeitado às ações de sujeitos morais. Na condição de paciente moral, sem condições de evitar os danos que as ações dos agentes morais lhes podem causar, quem está sujeito àquelas ações já está incluído na comunidade moral humana, quer queira, quer não, a mesma que o exclui por considerá-lo inapto ao exercício do direito. Mesmo não tendo direito algum, os sujeitos não-agentes, os pacientes morais (Regan) são seres vulneráveis ${ }^{9}$ aos atos e aos interesses dos agentes morais racionais. Aqui se revela o limite da filosofia moral tradicional com suas categorias de razão e autonomia centradas na finalidade de realizar apenas os fins de sujeitos da espécie Homo sapiens. A filosofia mo-

In contrast to moral agents, moral patients lack the prerequisites that would enable them to control their own behavior in ways that would make them morally accountable for what they do. A moral patient lacks the ability to formulate, let alone bring to bear, moral principles in deliberating about which one among a number of possible acts it would be right or proper to perform. Moral patients, in a word, cannot do what is right, nor can they do what is wrong." The case for animal rights. Berkeley; Los Angeles: University of California Press, 1983, p. 151-152.

Conforme Lawrence Becker, numa relação deve haver certas características, para que se possa considerar os sujeitos a ela como inter relacionados moralmente. "[...] os seres agem uns em favor de, com, ou contra os outros. [...] podemos ter relações, no sentido referido, com muitos tipos de animais, e, praticamente, com todos os seres humanos. Nessas relações, nosso reconhecimento verdadeiro da dependência é um dos fatores que determina a distância social. E, quanto maior a dependência, menor a distância social." BECKER, Lawrence. The priority of human interests. In: REGAN, Tom; SINGER, Peter. ARHO, p. 87.

8 Confira análise minuciosa desta questão no artigo, FELIPE, Sônia T. "Por uma questão de justiça ambiental”. Cf. Revista ETHIC@, Florianópolis, jul. 2006, www.cfh.ufsc.br/ethic@/et53art1Sonia.pdf, p. 5-31

- Emprego esse termo para designar a condição na qual as ações realizadas por um sujeito moral, para alcançar o benefício próprio, podem afetar positiva ou negativamente outro, na condição de paciente moral. Isso aplica-se a todos os seres vivos, conforme o estabelece Kenneth GOODPASTER em seu artigo, On being morally considerable. In: ZIMMERMANN, Michael E. Org. Environmental Philosophy: from animal rights to radical ecology. New Jersey: Prentice Hall, 1998, p. 56-70. Ver, ainda, Paul W. TAYLOR, Respect for nature. New Jersey: Princeton University Press, 1986; Tom REGAN, The nature and possibility of an environmental ethic. In: ENVIRONMENTAL ETHICS. University of New Mexico, Spring 1981, v. 3, n. 1, p. 19-34. Cf. também FELIPE, Sônia T. Valor inerente e vulnerabilidade: critérios éticos não-especistas na perspectiva de Tom Regan. In: ETHIC@, Florianópolis, jul. 2006, www.cfh.ufsc.br/ethic@/et53art9Sonia.pdf , p. 125-146; ALMEIDA, Julia Aschermann Mendes. A ética ambiental de Tom Regan: crítica, conceitos, argumentos e propostas. In: ETHIC@, Florianópolis, jul. 2006, www.cfh.ufsc.br/ethic@/et53art10Julia.pdf , p. 147-151. 
ral tradicional não consegue demover esses sujeitos de sua posição soberba, a mesma que os leva a destruírem, como se fossem banais, o bem-estar e a vida de outros seres que, a seu próprio modo, não precisam ser dotados de razão nem de linguagem lógico-formal para alcançarem seu bem-estar específico. Enfim, com tal matriz cognitiva não saímos da condição de tirania na qual nossa concepção de domínio moral nos enredou.

\section{Proposta de redefinição da constituição da comunidade moral}

Contrariando a tradição que concebe a ética e a justiça apenas para sujeitos dotados de personalidade moral, filósofos morais contemporâneos propõem outros critérios para a definição da sujeição moral à luz do duplo sentido do conceito de sujeito, acima sugerido. Se há agentes morais sujeitos de sua ação, isso não quer dizer que suas ações não afetem outros, não na condição de sujeitos da ação praticada, mas na de sujeitos a ela. Uma ação moral afeta diretamente outros sujeitos, podendo estes ser dotados de razão e capazes de linguagem conceitual abstrata, portanto racionais, ou simplesmente sujeitos a interesses biológicos e psicológicos naturais, sujeitos morais naturais.

Basta, nesse sentido, que uma determinada ação seja capaz de afetar outros sujeitos de interesses, para que ela deva ser considerada parte do âmbito da moralidade de sujeitos racionais. Na tradição, a natureza da ação é moral, ou não, dependendo da natureza do paciente moral. Se quem sofre a ação, não for um sujeito moral, o sujeito que a pratica não tem deveres positivos nem negativos diretos em relação a ele. A tradição moral considera apenas quem tem estatura moral como digno de respeito moral.

Na crítica a essa tradição, é a natureza da ação, isto é, o fato mesmo de afetar positiva ou negativamente o bem-estar próprio do outro, que indica o âmbito alcançado pela moralidade..$^{10}$ Ações capazes de afetarem o interesse de quaisquer sujeitos (sujeitos a elas ou sujeitos delas) são ações do âmbito da moralidade, devendo ser julgadas válidas, ou não, de acordo com sua capacidade de preservar ou de destruir o bem próprio dos que serão atingidos por ela. ${ }^{11}$

10 Cf. GOODPASTER, Kenneth E. On being morally considerable. In: ZIMMERMANN, Michael E. (Ed.). Environmental Philosophy: From Animal Rights to Radical Ecology. $2^{\text {nd }}$ Edition. New Jersey: Prentice Hall, 1998, p. 56-70. Ao definir os dois grandes desafios da ética contemporânea, Goodpaster aponta a exigência de se identificar "o bem que a moral visa promover levando-se em conta a perspectiva do 'paciente'moral, seu próprio bem, não a do agente moral, p. 57; FELIPE, Sônia T. Da considerabilidade moral dos seres vivos: a bioética ambiental de Kenneth E. Goodpaster. In: ETHIC@, www.cfh.ufsc.br/ethic@/et53art7Sonia.pdf, p. 105-118; NEGRÃO, Silvio Luiz. O critério da vida para uma ética ambiental: concepção, filiação, conceitos, argumentos e propostas. In: ETHIC@, www.www.cfh.ufsc.br/ethic@/et53art8Silvio.pdf , p. 119-124.

${ }_{11}$ Seguindo a mesma tese de Goodpaster, referida na nota anterior, Paul W. Taylor assim se expressa: "From the perspective of a life-centered theory, we have prima facie moral obligations that are owed to wild plants and animals themselves as members of the Earth's biotic community. We are morally bound (other things being equal) to protect or promote their good for their sake. [...] Such obligations are due those living things out of recognition of their inherent worth. They are entirely 
Na perspectiva crítica da ética prática contemporânea, podemos citar os esforços de Kenneth Goodpaster, Tom Regan e Paul Taylor, para redefinir o âmbito da ética e da justiça, visando contemplar os interesses de animais e ecossistemas. Para eles, a sujeição à moralidade não se dá exclusivamente pela posse da razão, considerada como a habilidade característica dos sujeitos da ação, mas pela vulnerabilidade ao dano. ${ }^{12}$ Esta é comum a sujeitos da ação e a sujeitos à ação, portanto, a agentes morais racionais e a pacientes morais naturais, sejam estes dotados de razão, no caso de humanos, que perdem a potência dessa faculdade, mas não a potencialidade dela, ou não-humanos, no caso de animais e ecossistemas vegetais.

A racionalidade, conforme a concebem Goodpaster, Regan e Taylor, é um critério que designa apenas os sujeitos que devem responder por suas ações. São estes os únicos que podem julgar se o que fazem beneficia ou prejudica os que são afetados por seu fazer. Mas, a ação moral abrange interesses de sujeitos que não podem julgar, não podem avaliar, não podem se proteger nem se defender de atos praticados por sujeitos dotados da plena posse da razão. Se a racionalidade é a marca da agência moral, a vulnerabilidade o é da paciência moral. Uma ética que se preze deve considerar os deveres morais a partir dessa redefinição.

Para a ética prática, nessa perspectiva crítica, há duas categorias de sujeitos morais: a dos sujeitos agentes, dotados de autonomia moral e, portanto, capazes de ações resultantes do seu querer; e a dos sujeitos pacientes, vulneráveis àquela ação específica, ainda que em outras interações sejam eles também agentes plenos de potência em sua vontade.

Quando nos referimos aos pacientes morais, não necessariamente nos referimos a sujeitos absolutamente destituídos de razão. Mesmo detentores de racionalidade, linguagem, consciência e pensamento, sujeitos morais racionais, estão sujeitos a interesses e decisões alheias. A condição de sujeito moral agente não é absoluta. A de paciente moral pode ser absoluta, no caso de sujeitos que sofrem as ações dos outros e jamais podem lhes causar mal, deliberadamente; ou relativa, quando se trata apenas da condição natural na qual cada um de nós interage com outros em situações nas quais a liberdade desse outro é maior para tomar decisões que nos afetam, do que nossa prerrogativa para impedi-lo de tomar tais decisões.

additional to and independent of the obligations we owe to our fellow humans. [...] Their wellbeing, as well as human well-being, is something to be realized as an end in itself." The Ethic of Respect for Nature. In: ZIMMERMANN, Michael E. (Ed.) Environmental Philosophy: From Animal Rights to Radical Ecology. 2nd Edition, New Jersey: Prentice Hall, 1998, p. 71-86.

12 Para Tom Regan, o dano pode ser compreendido como qualquer diminuição do bem-estar próprio da natureza específica de um ser vivo, ainda que esta diminuição não seja acompanhada diretamente da dor. Por isso, Regan prefere o termo sofrimento, mais amplo do que o de dor, para abordar a condição na qual animais não-humanos perdem a liberdade de mover-se para prover-se na forma natural que lhes é conveniente, e sofrem privações devidas ao tratamento que humanos thes infligem quando os usam e exploram para se beneficiarem. Cf. REGAN, Tom. TCAR, 1983, p. 94103; 94-96; 187-194; 262-263. 
Se reconhecemos que o fato de estarmos vivos nos coloca na condição vulnerável, reconhecemos que, mesmo sendo sujeitos dotados de razão, nem sempre agimos com autonomia moral plena, se é que alguma vez o fazemos. Ao falar de moralidade, falamos de uma condição na qual todos os sujeitos morais racionais podem afetar, negativa ou positivamente, os interesses de outros, mesmo quando estes últimos não têm poder para impedir os danos, nem para buscar benefícios. Nesse caso, o sujeito à moral encontra-se na condição de paciente moral racional, devido a sua vulnerabilidade moral temporária ou definitiva. Se for uma condição temporária de sujeição moral, tão logo as circunstâncias que definem essa menor liberdade sejam superadas, esse mesmo indivíduo voltará a agir na condição de agente moral racional, podendo causar dano a outros que se encontrem sujeitados a ele.

Sem o reconhecimento dessas diferentes formas de sujeição moral (agência e paciência moral), não damos um passo adiante na construção de um modelo ético que possa atender às exigências da inclusão de novos sujeitos de direitos morais na reflexão filosófica contemporânea. Admitida a teoria da variabilidade da sujeição moral - a teoria da agência e da paciência moral -, está dada, então, a possibilidade de inclusão de novos sujeitos de direitos na comunidade moral, animais não-humanos e ecossistemas vegetais, por exemplo, considerando-se sua vulnerabilidade aos danos que a agência moral pode causar.

\section{Novos sujeitos morais}

Desde o texto de Humphry Primatt, The Duty of Mercy, escrito em $1776,{ }^{13}$ os animais sensientes aparecem como sendo os pacientes morais mais vulneráveis aos interesses humanos, merecendo, por isso, ser incluídos no âmbito da consideração moral, pelo menos por seu interesse em não sentir dor nem sofrer. Seguindo Primatt, em 1789, Jeremy Bentham escreve, em Uma introdução aos princípios das morais e da legislação, ${ }^{14}$ que, a ética nunca alcançará plenitude enquanto os sujeitos racionais não reconhecerem que a dor e o sofrimento são os eixos sobre os quais a moralidade humana deve ser conduzida.

No século XX, Goodpaster, Regan e Taylor, para além de aceitarem as críticas formuladas por Primatt e por Bentham aos filósofos morais tradicionais, estabelecem que a ética genuína deve considerar o bem de todos os seres vivos capazes de sofrer danos causados pelas ações de sujeitos racionais, como o eixo sobre o qual deve ser constituída. Temos, nas teorias daqueles três autores, uma proposta de redefinição da ética. Nela, a teoria da sujeição acima apresentada passa a ser o recurso que permite a redefinição da comunidade moral humana para além de

${ }^{13}$ Cf. FELIPE, Sônia T. Fundamentação ética dos direitos animais. O legado de Humphry Primatt. In: REVISTA BRASILEIRA DE DIREITO ANIMAL. Instituto Abolicionista Animal, IABA, Salvador, v. 1, n. 1, jan./dez. 2006, p. 207-229.

14 São Paulo: Abril Cultural, 1979. 
sujeitos capazes de raciocinar, pensar e articular seu pensamento numa linguagem formal. A comunidade moral humana é constituída de sujeitos morais agentes e de pacientes morais, em outros termos, de agência e paciência moral.

Plantas, animais e humanos, para citar apenas o que é vivo, podem sofrer danos. São, pois, pacientes morais naturais, sempre que os danos resultarem da ação de agentes morais à qual os primeiros não podem opor resistência. Humanos dotados de raciocínio podem causar danos, quando buscam realizar seus próprios interesses. A moralidade visa justamente orientar sujeitos morais racionais agentes em suas decisões e ações, de modo que estas não causem aos demais, que se encontram na condição de pacientes morais, danos que os primeiros não gostariam que lhes fossem causados, caso se encontrassem em situação semelhante. Na concepção moral de Goodpaster, Regan e Taylor, temos deveres diretos em relação a todos os seres vulneráveis, por uma questão de coerência: quando estamos em situação vulnerável, por exemplo, numa unidade de tratamento intensivo, não suspendemos o dever dos outros de não nos causar mal.

Nessa perspectiva, animais e ecossistemas vegetais passam a ser incluídos no âmbito da comunidade moral humana, não por sua capacidade de formular juízos morais, mas por sua condição de vulnerabilidade aos benefícios ou danos que juízos morais formulados por agentes racionais podem produzir, quando estes se esquecem de que suas ações afetam positiva e negativamente o interesse de outros que não podem resistir ou opor-se a elas.

\section{Alcance da redefinição da comunidade moral}

Assim considerada a constituição da comunidade moral, deve-se entender que há deveres morais positivos e negativos, não apenas em relação a sujeitos racionais, mas também em relação a sujeitos não-racionais, pacientes morais naturais. Deve-se, ainda, compreender que o dever de justiça é um dever direto. Pacientes morais naturais não são meros meios (coisas vivas) para servir aos interesses de agentes morais racionais. ${ }^{15} \mathrm{O}$ dever direto positivo implica dar assistência a todos os seres capazes de sofrer danos em seus interesses pela intervenção de ações que visam beneficiar os interesses de sujeitos morais agentes. O dever direto negativo implica reconhecer que, em relação a sujeitos morais naturais (pacientes morais), devemos nos abster de todo ato capaz de lhes subtrair os meios ou condições necessários ao bem-estar próprio de sua espécie viva.

Por fim, redefinindo a comunidade moral, a partir dessa nova concepção de agência e paciência moral, reconhecemos que há um bem próprio a todos os seres capazes de sofrer com nossas ações, que seu bem não é um valor instrumental para nosso próprio bem, mas um bem que é deles, independentemente do quanto

15 Cf. FELIPE, Sônia T. Por uma questão de justiça ambiental. Perspectivas críticas à teoria da justiça de John Rawls. In: ETHIC@. Revista Internacional de Filosofia da Moral. Florianópolis: v. 5, n. 3, p. 5-31, jul. 2006. Disponível no site: www.cfh.ufsc.br/ethic@/CAPA53.htm 
somos capazes ou não de julgar que seja bom viver nas condições naturais propiciadas por sua espécie. ${ }^{16}$

Fundada nessa nova concepção, a ética poderá superar a tricotomia moral da qual hoje padece: a fundamentação dos direitos humanos, a fundamentação dos direitos animais, a fundamentação dos direitos ambientais, as últimas sempre na perspectiva do valor instrumental, isto é, com vistas a beneficiar a espécie humana, portanto, antropocêntrico-especista. ${ }^{17}$

$\mathrm{Na}$ nova perspectiva ética, continua-se a reconhecer que só há um sujeito moral agente, o dotado da capacidade de distinguir conceitos como os de bem e mal, e de operar com eles com vistas a evitar causar o mal e a propiciar o bem, ao agir, e pelo menos dois conceitos de sujeitos morais pacientes: um, destinado a contemplar sujeitos morais racionais na condição de pacientes das ações alheias, quando estão em condições nas quais a posse da razão não os protege de danos que outros lhes possam causar (este é o caso de qualquer ser humano dotado de razão), e outro, pacientes morais naturais, para designar os sujeitados às ações morais que não possuem a racionalidade lingüístico-formal requerida pela filosofia moral tradicional para a inclusão no âmbito da comunidade moral humana, mas constituem necessariamente essa comunidade, pelo simples fato de poderem ser afetados por danos causados a eles pelos interesses de sujeitos morais racionais. Nesse caso, a vulnerabilidade ao dano passa a ser a condição necessária e suficiente para caracterizar um sujeito como membro da comunidade moral e digno de justiça na distribuição dos bens naturais ambientais, por sua condição de paciência moral, mesmo que esse sujeito não seja representante da agência moral apreciada pela tradição.

\section{Referências}

BECKER, Lawrence. The priority of human interests. In: REGAN, Tom; SINGER, Peter. Animal Rights Human Obligation. New Jersey, Upper Saddle River: Prentice Hall, 1989.

FELIPE, Sônia T. Alcance e limites da Declaração Universal do DDHH. In: AGUIAR, Odilio Alves; PINHEIRO, Celso de Moraes; FRANKLIN, Karen. Filosofia e Direitos Humanos. Fortaleza: Editora da UFC, Série FiloSofia, 2006.

FELIPE, Sônia T. Fundamentação ética dos direitos animais. O legado de Humphry Primatt. In: REVISTA BRASILEIRA DE DIREITO ANIMAL. Instituto Abolicionista Animal, IABA, Salvador, v. 1, n. 1, jan./dez. 2006.

Ver, TAYLOR, Paul W. Respect for nature. New Jersey: Princeton University Press, 1986, p 55. Faço a crítica dessa racionalidade instrumental presente na ética e na teoria da justiça de Rawls, indicando os limites e o alcance de seu modelo relativamente à necessidade de inclusão de animais não-humanos e da natureza física ambiental, dois novos sujeitos de direitos, numa concepção política de justiça que tenha pretensão real de validade universal. Veja, FELIPE, Sônia T. Alcance e limites da Declaração Universal do DDHH. In: AGUIAR, Odilio Alves; PINHEIRO, Celso de Moraes; FRANKLIN, Karen. Filosofia e Direitos Humanos. Fortaleza: Editora da UFC, Série Filosofia, 2006, p. 53-96. 
FELIPE, Sônia T. Por uma questão de justiça ambiental. Perspectivas críticas à teoria da justiça de John Rawls. In: ETHIC@. Revista Internacional de Filosofia da Moral. Florianópolis: v. 5, n. 3, p. 5-31, Jul. 2006. Disponível no site: www.cfh.ufsc.br/ethic@/CAPA53.htm.

GOODPASTER, Kenneth E. On being morally considerable. In: ZIMMERMANN, Michael E. Org. Environmental Philosophy: from animal rights to radical ecology. New Jersey: Prentice Hall, 1998.

KANT, Fundamentação da metafísica dos costumes. São Paulo: Abril Cultural, 1980.

RAWLS, John. Uma teoria da justiça. São Paulo: Martins Fontes, 1997.

REGAN, Tom. The case for animal rights. Berkeley; Los Angeles: University of California Press, 1983.

REGAN, Tom. The nature and possibility of an environmental ethic. In: ENVIRONMENTAL ETHICS.

University of New Mexico, Spring 1981, v. 3, n. 1.

ROUSSEAU, Do contrato social. 2. ed. São Paulo: Abril Cultural, 1978.

TAYLOR, Paul W. Respect for nature. New Jersey: Princeton University Press, 1986.

TAYLOR, Paul W. The Ethics of Respect for Nature. In: ZIMMERMANN, Michael E. (Ed.) Environmental Philosophy: From Animal Rights to Radical Ecology. $2^{\text {nd }}$ Edition, New Jersey: Prentice Hall, 1998.

TAYLOR, Paul W. Are humans superior to animals and plants? In: Environmental Ethics. University of North Texas, Summer 1984, v. 6, n. 2, p. 149-160.

WHITE, Alan. Why animals cannot have rights. In: REGAN, Tom; SINGER, Peter. Animal rights human obligation. $2^{\text {nd }}$. New Jersey: Prentice Hall, 1989. 